\title{
Die Onbekende Afrika
}

Die ou Latynse gesegde „ex Africa semper aliquid novi - uit Afrika altyd iets nuuts - is in die tweede helfte van die $20 \mathrm{e}$ eeu nog nie van alle waarheid ontdaan nie. Hierdie uitdrukking impliseer per slot van sake tog niks anders as onkunde oor diè kontinent nie. Eweso die bekende kwalifikasie: donker Afrika. Hierdie duisternis het seker nie net betrekking op die kennis- en beskawings- en morele toestande van die volke wat hulle vaderland hier het nie maar net soveel of meer nog op die onkunde van die wêreld ten opsigte van Afrika. Trouens, soos prof. Kimble in sy ,prospectus for a survey of Africa" tereg aandui: „Africa is no longer ignorant of us." Maar ons, d.w.s. die blanke westerse wêreld weet oor die algemeen so min van Afrika.

Treffend is dit dat die kennis van die weste oor die nuwe wêreld in omvang en diepte ongetwyfeld, en selfs ook sy kennis van die eeu-oue Ooste waarskynlik, groter is as van Afrika. Die nuwe wêreld! Wat die kontak-situasic betref is Afrika een van die oudste vastelande. Argeoloë neig al meer tot die konklusie dat Afrika in die nouste verband gebring moet word met die vroegste geskiedenis van die mensdom. Maar ook in die vroegste geskrewe geskiedenis figureer hierdie wêrelddeel al is dit dan hoofsaaklik net in sy noordelikste en noord-oostelike gedeeltes: Egipte, Soedan, Ethiopië. Hier het van die vroegste beskawings gebloei; hier het van die eerste Christelike gemeentes bestaan. Hier het Rome kolonies gehaad en van hier uit is Suidwes-Europa in die agtste eeu deur die More ingeval en tot aan die begin van die $17 \mathrm{e}$ ceu oorheers of ten minste beïnvloed.

Vir baie lank het die kennis en belangstelling ten opsigte van Afrika slegs om die periferie, om sy kuslyn gegaan. As obstruksie in die seeweg en handelsroete na die Ooste moes hy omseil word en het almal daarby betrokke hulle min of meer tevrede geag met kontakte, tydelike nedersettings, handels- en verversingsposte oral langs die kus.

(Eergte Referaat gehou voor die Afrika-seminaar van dle P.U. vir C.H.O., 20 Aug. 1957). 
Dit staan veral tot Stanley en Livingstone se krediet dat hulle, miskien yweriger ontdekkingsreisigers as sendelinge, ook die binnelande binnegedring het. Die uiteindelike koloniale ekspansie van die $18 \mathrm{e}$ eeu sou dié binnedringing sterk bevorder. En tog spreek die wyse waarop die verdeling van Afrika plaasgevind het boekdele van sowel die politieke en ekonomiese selfsug van die betrokke koloniale moondhede as van hulle onkunde omtrent die voorwerp van hulle begeerte.

Die vestiging van die koloniale gebiede in Afrika het ongetwyfeld die belangstelling van die kant van Europa in hierdie kontinent aangewakker. Maar die 20e eeu en veral die nagevolge van die eerste maar by uitstek van die tweede wêreldoorlog sou die eintlike stoot gee aan die aktiewe belangstelling, die begeerte na meer en diepergaande kennis as basis vir beleidsbepaling, politieke en administratiewe optrede, ekonomiese inisiatief en militêre strategie van die belanghebbende volke en state. Opmerklik is dit dat in hierdie fase verskeie volke wat nie deur die Afrika-verdeling van die $18 \mathrm{e}$ eeu of deur die toekenning van mandaatgebiede in 1919, 'n aandeel aan die kontinent verkry het nie, nou hulle belangstelling en invloedsfeer hierheen verskuif. Dit geld veral Rusland, Indië en die V.S.A.

'n Vlugtige oorsigtelike blik op die huidige belangstellendes en belanghebbendes by die gebeure in en toekoms van Afrika is nodig om ' $n$ beeld te verskaf van die posisie van hierdie vasteland in die hedendaagse wêreld. Dit is ook vir ons in Suid-Afrika nodig om kennis daarvan te dra ten einde ons plek in d:e situasie en ons verhouding teenoor die verloop van sake te kan bepaal.

In die eerste plek is daar natuurlik die inboorlingvolke self. Ongeletterd en beskawingsagterlik was hulle belangstelling tot onlangs meesal nog beperk tot hulle eie en besondere woongebiede en bestaansmoontl:khede. Dit sou eers die aanraking met en beïnvloeding deur die westerse kultuur vereis, en dan ook alleen na baie dekades van aanraking, om die mense van Afrika eintlik self tot 'n Afrika-bewussyn te laat ontwaak. Voorheen was hulle geestelike horison deur die Stam- en die Stamgebied bepaal. Die nuwe bewussyn sou ongelukkig tot 'n groot mate bepaal word deur ' $n$ afwerende houding, 'n negatiewe gesindheid teen blanke aanwesigheid en gesag en teen alles wat ingesluit en verstaan word onder die begrip kolonialisme. Daaruit groei die begeerte om „Batho ba Afrika," mense van Afrika, „Africans", te word as onderskeie enersyds van die stamlike en etniese differensiasie en andersyds van die ander groep van Europese herkoms. Aansluitend hierby ont-1 
staan die Sjibbolet: „Africa for the Africans!” Of hierdie belangstelling veel meer om die lyf het as 'n emosionele kleed sonder veel werklike kennis of gebalanseerde oordeel oor die situasie soos dit werklik bestaan of oor die implikasies van wat bepleit word, is 'n ope vraag. Nogtans kan die woelinge en wordinge oor die lengte en breedte van Afrika nie veronagsaam word nie. Ons en hulle belang en toekoms vereis ' $n$ noukeurige bestudering daarvan.

Van heelwat meer materiële substansie is die belangstelling van daardie Europese moondhede met koloniale belange in Afrika: Engeland, Frankryk, België, Portugal en Spanje. Dit spreek vanself dat die administrasie en ontwikkeling van koloniale gebiede, onder welke administratiewe sisteem en beleid ook al, alleen geslaagd deurgevoer kan word indien die beherende instansie enige kennis dra van daardie gebiede: van hulle mense sowel as van die klimaat, natuurlike hulpbronne, e.d.m. Dit is seker nie oordrewe eensydig gestel as beweer word dat die kennis van en belangstelling in die menslike materiaal en potensiaal merendeels die meeste te wense oorlaat, selfs ook wanneer in die mode-opvatting van die middel van die twintigste eeu soveel geskerm word oor die regte van die mens en die vrymaking van die Afrika-volke op elke forum geproklameer word nie. Dit bly egter' $n$ feit dat hierdie moondhede gesamentlik en afsonderlik veel gedoen het om Afrika oop te maak vir die wêreld. Daarmee bedoel ek nie net territoriaal en fisies toeganklik en bewoonbaar nie, maar ook wat navorsing en studie betref, onderwys en sending, hospitalisasie en vreedsame verhoudinge. Afsonderlik en in enkele opsigte ook gesamentlik, het hierdie instansies veel gedoen om materiaal oor Afrika te versamel en beskikbaar te stel wat vir die wetenskap van die allergrootste betekenis is. Hieronder kan veral genoem word: die Royal Institute of International Affairs, die Royal Empire Society, die Royal African Society, dic International African Institute (almal met hoofkwartier te Londen terwyl die Colonial Office naas sy uitstekende boekery ook vir uiters waardevolle publikasies verantwoor(lelik is) die Inter-African Information Bureau for Soil Conservation and Land Utilization te Parys, die Koninglike Tropiese Instituut, Amsterdam, Instituut voor Afrikanistiek, Leuven. Onder beheer van enkele van hierdie state het ook in Afrika ' $n$ aantal navorsingsinstansies ontstaan soos die Institut Francois d'Afique Noire (Dakar), Institut d'Etudes Centrafricaines (Brazzaville), Institut pour la Recherche Scientifique en Afrique Centrale (Costermansville, Belgiese Kongo), die Rhodes-Livingstone Institute (Livingstone, N.R.), die Scientific Council for Africa South of the 
Sahara (Kenia), East African Agriculture and Forestry Research Organization (Nairobi).

In hierdie verband moet ook genoem word die werk van 'n vroeëre koloniale belanghebbende in Afrika, nl. Duitsland. Laasgenoemde het op verskeie terreine belangrike bydraes gelewer met betrekking tot ons kennis van Afrika. Onder die belangrikstes is sy „Kolonialforschung”, sy volkekundige belangstelling, sy sendingaktiwiteite en algemene ontdekkings- en ondersoekingsreise. Die name van Frobenius en Baumann, van die Afrika-afdelings van die Duitse volkekundige musea, van die Rhynse sendinggenootskap en sendelinge is ten nouste verbonde aan ons Afrikakunde.

Die verbondenheid van hierdic Europese koloniale moondhede met Afrika is sterk en diep. Van Spanje hoor ons waarskynlik die minste maar sy geskiedenis is tot so onlangs as die uitbreek van die Spaanse burgeroorlog ten innigste verbind met die Afrikaanse vasteland en dit is begryplik dat genl. Franco na Afrika sal kyk met meer as koloniale belangstelling. Van Portugal met sy twee groot gebiede aan die oosen weskus verneem ons gewoonlik weinig maar tydens die ontvangs van Suid-Afrika se Goewerneur-generaal het ons ook uit daardie oord bekommernis verneem oor gebeure hier ons ons kontinent. Vir Engeland as wêreldmoondheid, met groot belange in die woelige Midde-Ooste, die verlies van 'n oosterse ryk en lank gevestigde belange in Afrika het hierdie wêrelddeel van toenemende belang geword sowel wat verdediging van olie- en ander sake in die naby-asiatiese wêreld betref as goedgesindheid van vrywordende Afrika-state in die Britse Gemenebes. Ook van België word nie veel verneem oor die Kongo en sy plek in Afrika nie, maar dit verg nie veel insig en verbeeldingskrag om te begryp dat België met intense aandag die gebeure in Afrika dophou en sy koloniale administrasie en -beleid probeer formuleer en toepas om die Kongo ten minste as 'n bondgenoot - 'n vriendskaplike en veral winsgewende bondgenoot - te behou nie. Waar Frankryk sy Afrika-besittings nog altyd as integrale dele van die Franse Unie beskou het, kan die uitspraak van dic Franse president dat daar nie te dinke val dat Frankryk sy burgers in Afrika aan hulle lot gaan oorlaat nie, heel goed begryp word. Dit is nie net geld en goud en prestige wat Parys aan Afrika bind nie, maar ook bloed en sentiment.

Tradisioneel en histories is ook die Midde-Ooste ten nouste verbonde met Noord-Afrika. Sowel die ou Suez-landengte as die see-engte vanaf die Suezgolf tot by die straat van Bab-cl-Mandeb en ook nog 
verder ooswaarts tot verby Aden, was nooit 'n werklike versperring tussen die noord-oostelike dele van die Afrikaanse vasteland en die Arabiese wêreld nie. Die Sahara het blykbaar 'n groter barriere gevorm tussen noordelike en Midde-Afrika as die Rooi-see tussen noord-oostelike Afrika en die Arabiese skiereiland. Maar afgesien van die territoriale bereikbaarheid is daar twee verdere sterk bande wat hierdie dele van die twee groot kontinente bind, $\mathrm{nl}$. 'n nasionale en 'n religieuse, met name die Arabiese taal- en kultuurverwantskap en die Mohammedaanse geloofsgemeenskap. Op grond hiervan handhaaf die Midde-Ooste tradisioneel 'n aktiewe belangstelling in Noord-Afrika en sy lotgevalle. Die naoorlogse politieke situasie in hierdie gebied, die erkenning van Israel en die opkoms van Egipte met die gevolglike botsing, is allesins bevorderlik vir 'n verhoogde belangstelling en meebelewing in genoemde oord. Maar ook hier gaan die belangstelling blykbaar nie ver buite die perke van nasionale sentiment en godsdienstige emosie nie en is dit veral gerig op die Arabies-Islamitiese dele van Afrika.

Die „nuwe belangstelling”, d.w.s. die aandag van vroeër onbekende instansies, is m.i. van besondere betekenis. Eerstens moet genoem word die speurende oog van kommunistiese Rusland wat via die MiddeOoste oor Afrika dwaal en sy rooi vingers wat begin woel en werskaf onder die donker volke van hierdie wêrelddeel. Dit is algemene kennis hoedat die Kremlin dwarsoor Afrika, in elke gebied en onder elke volk sy gistingswerk aan die gang gesit het - ondergronds natuurlik in organisasies van allerlei slag en aard, van die geringste rooskleur tot bloedrooi, van skynbaar suiwer demokraties tot deur-en-deur bolsjewisties. Die opslae daarvan word gevind in feitlik elke opstootjie en in alle onluste in die koloniale gebiede; dit loer deur die skerms op die verhoog van die Egiptiese drama; oral is die stempel van Moskou se werkwyse aan te wys; oor die eter kom sy sirene-sang. Die opkomende nasionalismes word in Moskou beskou as 'n uitmuntende geleentheid en camouflage waaragter sy agente hulle werk kan verrig. Volgens onderpresident Nixon van die V.S.A. word Afrika vandag deur die kommunistiese leiers van net soveel belang beskou as China 'n kwart-eeu gelede.

In hierdie situasie is van besondere belang die deeglike studie wat die Kremlin-instansies maak van Afrika as 'n potensiële infiltrasiegebied en die kennis wat hulle dra van die sosiale, ekonomiese en politieke toestande en bowe-al van alle griewe as voedingsbron vir sy kommunistiese suurdeeg.

Naas Rusland het 'n ander Asiatiese kolos - al is dit voor- 
lopig nog met voete van klei - sy belangstelling in Afrika luidkeels te kenne begin gee. Die verbintenis van die verder geleë Ooste met Afrika waarvan ons o.a. reeds lees in die boek Ester - die honderd sewe-en-twintig provinsies, van Indiê af tot by die kus onder die bewind van Ahasváros - het lank reeds langs die kus van Oos-Afrika 'n Indiese neerslag en invloedsfeer op handelsgebied laat ontstaan. Maar gedurende die afgelope dekades het dit 'n soort konsentrasiepunt van Indiese immigras:e na Afrika geword. Bykans driekwart-miljoen Indiërs bevind hulle aan die Afrikaanse ooskus vanaf Durban tot by Mombasa. Die belangstelling vanuit Delhi is nie beperk tot die verblyf en welsyn van hierdie nietige persentasie van die massale Indiese bevolking nie. Dit is van breëre omvang en sterker politieke kleur. In Ghana, waar nouliks 300 Indiërs woon, het Indië 'n kommissaris benoem en word die "India News" weekliks in sy duisende versprei. In 1946 is in die Indiese Hoërhuis gesuggereer dat Brittanje gevra word on sy mandaat oor Tanganjika aan Indië oor te dra. Mauritius is vir alle praktiese doeleindes - met 67 persent van sy bevolking lndiërs - 'n annex van Nehru se staat. Die Bandoeng-konferensie teen blanke kolonialisme in Afrika, is die geesteskind van die Indiese Staatshoof. Sy drome om by hierdie geleentheid prominent te figureer om hoog op te gee as pleitbesorger en kampvegter vir die onderdrukte volke van Afrika is, ongelukkig vir Nehru, verdryf deur die oorheersende optrede van die leier van kommunistiese China. Tans bied de V.V.O. die forum vir hierdie selfgeroepe apostel vir die redding en bevryding van Afrika. Tot oormaat van ramp vir Afrika en vir die rassebetrekkinge, is die metodes waarvan Indië hom verder bedien dié van geldelike hulp aan versetters in Suid-Afrika, opruiende radio-propaganda in Oos-Afrika, vyandige lektuur in Kenia, stimulering van onluste in Njassaland en Madagaskar.

Dit was veral die onluste in die Midde-Ooste, die opkons van Nasser in Egipte en die Russiese insypeling in Afrika - almal faktore wat die oliebelange van die V.S.A. in Wes-Asië bedreig - wat hierdie moondheid van die Nuwe Wêreld se belangstelling in Afrika besonder gaande gemaak het. In 'n artikel in 'n onlangse nommer van die „New York Times" word die stelling gemaak dat Amerika in die verlede weinig of geen belangstelling in Afrika getoon het nie. Nou word hy deur omstandighede egter gedwing om dit te doen. Onder 'n vlag van idealistiese ideologië, w.o. die bevryding van Afrika en die handhawing van vrede onder die Arabiese volke, word daar per slot van sake ook 
maar weer 'n vrag van konkrete, materiële belange - uraan, olie, beleggings, afsetgebied, - vervoer.

In 'n "prospectus for a survey of Africa” wat deur prof. dr. George H. T. Kimble opgestel is vir die Twentieth Century Fund (Febr. 1953), word naas die algemene en Amerkaanse onkunde betreffende Afrika, daarna verwys dat „Africa has almost certainly the largest untapped reservoir of material resources in the world... Secondly, it occupies a privotal position in a politically divided but economically interdependent world". Die belangrikheid van Afrika vir Amerika word sterk beklemtoon. „Furthermore, what is happening in Africa - socially, economically, and politically - is a portent, the rightful reading of which is mandatory for America as for Europe. This nation has fared ill long enough as it is from its misconceptions of an earlier Africa, and will assuredly fare worse if steps are not quickly taken to remove them".

Derhalwe bekla prof. Kimble hom oor die Amerikaanse onkunde betreffende Afrika. "In no matter what direction we turn, we are confronted with weighty indications of ignorance, not only of the basic geography of the continent, but also of the basic geography of the continent, but also of its highly differentiated economics, cultures, governmental forms and, perhaps most important of all, its fast-changing attitudes and ambitions. Africa is ignored in the schools and sidetracked in the colleges. From a not inconsiderable experience of both, I would venture to guess that less one student in a thousand has received a formal course of instruction in the geography of Africa by the time he graduates from high school, and that the odds are even larger for college graduates. Their chief mentor in African matters is the Hollywood film producer who, like the geographers of Swifts' day, tends to be more concerned with elephants than the towns." Hierdie beeld van gebrek aan belangstelling en van onkunde word voltooi deur verwysing na die afwesigheid van Afrika in Amerikaanse wetenskaplike literatuur, die gebrek aan ondersteuning vir Afrika-studie en die bestaan van slegs 'n handvol internasionaal erkende gesaghebbende geleerdes oor Afrikakulture en die feit dat amptenare in die V.S.A. wat met Afrika-sake te doen het, hulle kennis langs die moeilike weg van „trial and error" moes bekom.

Hoewel prof. Kimble meen dat die verdrywing van hierdie onkunde alleen deur' $n$ stormwind van opvoedkundige bedrywighede teweeg gebring kan word, skyn dit asof Amerika hiervoor nie terug deins nie. Daar bestaan allerlei aanduiding dat Afrika vanuit die periferie van 
belangstelling na die sentrum verskuif. Getuie hiervan is o.a. die genoemde "Survey of Africa" wat gefinansieer word deur groot kommersiële fondse in die V.S.A.; die stigting van ambassades in Marokko, Tunisië, Libië en Ghana; onder-president Nixon se aanwesigheid by die selfstandigheidsvierings van Ghana en sy daaropvolgende besoek aan die gebiede wat belang het by die waters van die Nyl; amptelike departementele belangstelling in die meer as 2000 studente uit Afrika aan V.S.A.-universiteite; die benoeming van 'n onder-minister vir Afrikaaangeleenthede; die herhaalde ekonomies gemotiveerde besoeke van gewese presidentskandidaat Adlai Stevenson. Onderwyl het verteenwoordigers van groot Amerikaanse fondse vir navorsingswerk in samewerking met die Amerikaanse ambassade in die Unie reeds ook te kenne gegee dat hulle geld beskikbaar hou vir omvattende en duur navorsingsprojekte waarin die klem veral op „contemporary African problems” sal val.

Ook in die Amerikaanse wetenskaplike en populêrwetenskaplike literatuur is die ontwakende belangstelling op te merk. Terme soos Mau Mau en "apartheid" is reeds goedbekende hoewel waarskynlik nog sleg begrepe terme in die land van die dollar. John Gunther se „Inside Africa”, Dvorin se „Racial Separation in South Africa”, C. Grave Haines se „Africa Today” en vele ander onlangse boeke, naas talryke tydskrifartikels en persverslae gee ' $n$ beeld van die toenemende belangstelling. Dat die objektiwiteit, oordeelkundigheid en wetenskaplike kwaliteit van baie hiervan nie op peil is nie, doen niks of van die feit dat Amerika Afrika begin raaksien nie. Die werk van Haines is veral van betekenis in die verband met die oog op die oorsprong daarvan, soos die samesteller dit dan ook erken: "This volume is in itself evidence of the seriousness of current intellectual interest in Africa, for it grew out of the Conference on Contemporary Africa which The Johns Hopkins University School of Advanced International Studies sponsored in Washington, in August, 1954, as part of a special graduate summer program devoted exclusively to African affairs. The fact that more than four hundred individuals - academicians, business men, government specialists - were willing to brave the sweltering heat of Washington in August in order to attend and participate in this conference is eloquent testimony to the size and enthusiasm of the group of scholars and professional people in the United States who are focussing their attention upon Africa".

En om nou nader tuis te kom: waar staan Suid-Afrika in hierdie verband? Dit word soms in korswil beweer dat die Drakensberge 
vir die Natallers en die Heksrivierberge vir die Bolanders die uitsig op die res van die Unie versper. In dieselfde sin sou ons kon beweer dat die Limpopo vir die deursnee Afrikaner tot onlangs nog te wyd was om die res van Afrika raak te sien - en dit nieteenstaande die woorde "noordwaarts!" groot en helder geskryf staan oor die blaaie van ons geskiedenis. Want die ou pioniers het in hulle noordwaartse gang en strewe hulle weinig gesteur aan beperkende grense en verskeie, onder wie die bekende Carolus Trichardt het tot ver in die noordeliker gebiede ingedring. Hierdie strewe was egter geensins gerugsteun deur 'n teoretiese kennis van die geografiese en politieke, volkekundige en godsdienstige, kommersiële en ander aspekte van die vasteland nie sodat die bereisde dele met hulle mense en dinge teen die agtergrond van Afrika en sy plek op die wêreldkaart besien en gewaardeer kan word nie. 'n Uiterste aanduiding hiervan was miskien dit, dat vir baie die Nyl sy oorsprong kort anderkant Pretoria gehad het en Jerusalem per ossewa vanaf die noordwestelike grense van Transvaal bereikbaar sou wees!

En selfs toe met vermeerderde en verbeterde onderwys die kennis beskikbaar geword het, het die politieke en kulturele situasie, 'n verbete stryd om nasionale en ekonomiese voortbestaan, veral die Afrikaanssprekende se blik en energie hier gevange gehou. Immers, die uitsig op die noorde is letterlik en figuurlik afgesny deur die Rhodespolitiek en ,het insluiten van het Boerenrepublieken" (Leyds). Voorasnogr sou die Afrikaner se belangstelling grotendeels beperk bly tot die gebied suid van die Limpopo behalwe vir sover enkele groepe kultuurgenote hulle in Angola, Rhodesië en Kenia bevind het. Maar hulle het dan ook die uiterste grense van ons gesigsveld op Afrika verteenwoordig.

Natuurlikerwys is die Suid-Afrikaanse blik sterker gevestig gewees op Wes-Europa, sy historiese en kulturele heimat. Begryplikerwys sou dit vir hom 'n duursame proses wees om die balans te vind tussen Europa en Afrika en die twee in die regte perspektief te sien. Hoewel die blanke wat inheems geword het in die suidelikste deel van Afrika, vir hom vroeg al die inklusiewe naam van Afrikaner toegeken het, het hy tog essensieel 'n Suid-Afrikaner gebly, grootliks geïsoleerd - geografies en geestelik - van die res van die vasteland waarop hy vir hom 'n vaderland gevind en gemaak het. En hoewel hy met al sy mag vasgekleef het aan hierdie vaderland sodat sy lot voortaan onafskeidbaar ingeweef sou wees met die res van die kontinent, het hy minder gou bewus geword van die kontinentale agtergrond van sy vaderland as die mense van grotendeels dieselfde Wes-Europese herkoms en tradisie 
in 'n ander kontinent Amerikaners en Amerikaansbewus geword het.

Dit was die toestand nieteenstaande die toegeëiende naam en die roeping wat op hom rus het as gekerstende en beskaafde volk. Hierdie houding is min of meer algemeen weerspieël in ons staatkunde, in ons onderwys, in ons daaglikse lewensbenadering. Oor die algemeen is Kimble se beeld van die V.S.A. se onkunde betreffende Afrika eweseer van toepassing op Suid-Afrika. Daar bestaan darem ook alle tekens dat die periode van onkunde en gebrek aan belangstelling aan die verbygaan is, dat d:e blanke in suidelikste Afrika ophou om oor Afrika heen slegs Europa en die Ooste, Australië en Amerika raak te sien. Dit skyn asof hy nou begin om vanuit Suid-Afrika ook Afrika raak te sien en vanuit Afrika die wêreld.

Daar is verskeie name te noem in die afgelope halfeeu van ons geskiedenis van leidende persoonlikhede wat 'n wyer Afrikavisie aan die dag begin lê het. Meesal was hulle nog uitsonderinge; profete wat hulle mense en hulle tyd vooruit was. Afgesien van alle strydpunte oor en die bitterheid en smarte van die afgelope wêreldoorlog en die Unie se deelname daaraan, kan dit nie ontken word nie dat genl. J. C. Smuts ' $n$ besonder belangrike aandeel daarin gehad het om Suid-Afrika se blik te verhelder en oor die Limpopo en Sambezie heen weer noordwaarts op Afrika te vestig. Hierdie begin is verder ook verstewig deur die na-oorlogse situasie. Die ontstaan van selfstandige, inheemse Afrikastate, die grypende hande en loerende oë van half-oosterse en oosterse state, strategie en verdediging, die oopgaande markte en afsetgebiede, die heidenvolke wat 'n uitdaging slinger aan kerk en sending - alles het daartoe bygedra om Afrika binne ons gesigsveld en ons belangstellingsfeer te bring.

Hierdie ontwakende en toenemende belangstelling merk ons die afgelope tyd ook in verskillende gebeure. Die Unie neem gereeld deel aan die konferensies van die Wetenskaplike Raad vir Afrika Suid van die Sahara. In die staat se Departement van Buitelandse Sake is 'n Afrika-afdeling gestig terwyl die energieke minister skakeling met belanghebbendes in Afrika onderhou. Ook die Suid-Afrikaanse Akademie vir Wetenskap en Kuns het oorgegaan tot die stigting van 'n Afrika-instituut. Verder moet onder die aandag gebring word die werksaamhede van die South African Institute of International Affairs, die stigting van Afrika-studiegroepe aan enkele Suid-Afrikaanse Universiteite. Die Transvaalse Onderwysdepartement skenk aandag aan die moontlikheid om in die skoolleerplanne Afrika 'n prominenter plek te gee. 
Afrika is vir die eerste keer op die kaart geplaas as 'n struikelblok op die handelsroete oorsee na die Ooste. Maar hy het daardeur ook positiewe ekonomiese betekenis verkry. Hierdie donker kontinent se "swart ivoor" het - afgesien van die matelose menslike ellende verbonde aan die verkryging daarvan - arbeid en rykdom tot in baie wêrelddele en vér afgeleë markte gebring. Dit het Amerika wel opgesaal met 'n kultureel-politieke en sosiaal-etiese Negerprobleem, maar dit het ook verhewe belangstelling in Afrika gestimuleer deur die bestryding van die slawehandel. Verder was daar ook sy goud - vandag nog saam met sy uraan - en ander edelgesteentes, sy ivoor, sy speserye, sy landbouprodukte. In toenemende mate het Afrika deur sy klein groepie blanke ondernemers ' $n$ altyd belangriker leweransier op die wêreldmarkte geword. En vir die geindustraliseerde Europa en Amerika is van miskien nog meer betekenis dat Afrika se inboorlingbevolking ' $n$ belowende afsetgebied vorm vir hulle nywerheidsprodukte en vir ander dat sy ruimtes 'n moontlike „Lebensraum" bied vir drukkende bevolkingsoorskotte.

Tot krediet van die Westerse volke moet tog gekonstateer word dat die aanvanklike en oorwegende ekonomiese belangstelling aangevul is deur meer humane oorwegings en idealistiese motiewe soos die bestryding van die slawehandel en die verkondiging van die Evangelie. Gesamentlik het dit gelei tot gesagsvestiging in die vorm van kolonies en protektorate wat verdere ekonomiese, opvoedkundige, politieke en militêre aandag geverg het. Die militêre as beskermende funksie in verband met die ander belange, tree vandag baie sterk op die voorgrond. In hierdie lig moet onderpresident Nixon se besoek aan die Nyllande gesien word. Die dreigende kookpot van die Midde-Ooste waarin die V.S.A. maar steeds probeer om 'n finale ontploffing te voorkom, maak Noordoos-Afrika militêr uiters belangrik. Terselfdertyd moet hier 'n grens gestel word aan Russiese aspirasies. Volgens die London Times sal dit nie meer lank duur voordat ondermynende magte vanaf die Arabiese Skiereiland na Afrika oorsteek nie. Verstaanbaar is derhalwe die beweging in Brittanje om sy hoofkwartier vir die Midde-Ooste na OosAfrika oor te plaas.

Hierdie kompleks van faktore het binne dle huldige werelds:tuasie die veelsydige strategiese posisic val Afrika sterker as ooit in dic verlede gaan beklemtoon: En hierin is en mag Suid-Afrika nie afsydig staan nie. As Altmeyer Suid-Afrika „Europas letzte Grenze” mag noem, is dit ewe waar dat Suid-Afrika se grense binne sy verdedigingsveld lê. Militêr is Suid-Afrika in heginsel en deur politieke praktyk reeds inge- 
skakel in die verdedigingsplan vir Afrka. Vir geruime tyd is sy verbondenheid met die res van die kontinent reeds erken en bek!emtoon in samewerking betreffende die bestryding van menslike en dierlike en landboukundige epidemies en plae. Om 'n bevredigende oplossing vir die rassevraagstuk te vind vereis 'n Afrika-blik en wye samewerking. Die ontwakende Afrika met sy groeiende nuwe behoeftes is Suid-Afrika se aangewese mark. Die tegniese ontwikkeling maak tot 'n groot mate aanspraak op geskoolde leiers en werkers uit die (blanke) suidelike gebiede. Maar bo al hierdie oorweginge staan vir Suid-Afrika sekerlik sy roeping om Afrika te open en te behou vir die Christelike beskawing soos Totius dit digterlik-profeties in sy digwerk „Die Trek van Loerewaens” gesien het. Ek sien dit as ons grootste enkele historiese taak en roeping in die volgende eeu. Daarvoor moet ons ons voorberei deur ywerige studie en ondersoek en geïnspireerde optrede.

Die proses van 'n ontwakende belangstelling in die kontinentale grense en agtergrond van ons vaderland en die roeping van ons volk teenoor hierdie vasteland en sy mense, mag seker en kan ook nie ongemerk aan die Potchefstroomse Universiteit vir Christelike Hoër Onderwys verby gaan nie. Uit hierdie besef is die besluit gebore tot die hou van gereelde seminare oor Afrika. Die stap geniet die heelhartige steun en goedkeuring van Senaat en Raad. In verskillende departemente word vir geruime tyd al in mindere of meerdere mate aandag aan Afrika in doseeren navorsingswerk gegee. Hopelik sal die werk van hierdie seminare daartoe bydra dat die werk meer in verband gebring en sterker gestimuleer word en moontlik ook meer fasiliteite daarvoor beskikbaar gestel word. Dit was nooit die bedoeling van hierdie stigting om die studie van Afrika te bevorder ten koste van kennis van en oor Suid-Afrika nie, maar veel eerder om ons kennis van Suid-Afrika te verruim en te bevrug deur dit te sien teen die groter agtergrond van die vasteland.

Die doel van hierdie onderneming sien ek dus as drieledig t.w. algemene stimulering van belangstelling in die Afrikaanse kontinent en alle aangeleenthede en aspekte in die verband; verder die koördinering van kennis, studiemateriaal en navorsingsprojekte en ten slotee - en miskien die belangrikste - om self studie en navorsing te onderneem en sodoende die bestaande kennis uit te brei en tot ander se beskikking te stel of self aan te wend.

Die miducle warvan ons ons sal bedien, is in die eerste plek d:e gereelde seminare. As inleiers sal optree verskillende vakdosente van ons Universiteit en by geleentheid selfs ook gevorderde studente. Maar 
namate fondse en geleenthede dit toelaat behoort ook sprekers uit ander Universiteite en uit ander lewenskringe uitgenooi te word hetsy SuidAfrikaners of besoekers van elders -- in elk geval persone wat soveel moontlik die stempel van kenners van Afrika dra.

Hierby moet die uitbouing kom van die Universiteitsbiblioteek en van die departemente wat regstreekse belang daarby het on sodoende 'n verteenwoordigende Afrika-afdeling in boekery, kaarte, lopende tyd skrifte en ander studiemateriaal te huisves. Dit sal nodig wees om hiervoor by die Raad aan te klop om 'n besondere toelae bo en behalwe wat spesifiek vir die afsonderlike departementele gebruik nod' $\mathrm{g}$ is. Begin sal moet word met 'n opname, departementsgewys, van die materiaal waaroor ons reeds beskik.

In die toekoms - hopelik in die nabye toekoms sien ek die verwesenliking van 'n studiefonds wat dosente en studente in staat sal stel om Afrikaprojekte as narvorsingstemas aan te pak en veral om studiereise in en deur Afrika te onderneem.

As vanselfsprekend moet dit aanvaar word dat die nouste samewerking gesoek moet word met ander instansies van dieselfde aard en ooreenkomstige doelstelling, sowel deur oor-en-weer besoeke, uitruil van gegewens, beskikbaarstelling van inligting e.d.m. Uit die aard van die saak sal ons aanvanklik eerder ontvangers as gewers wees. Deur goeie beplanning, ywerige optrede en hartlike samewerking behoort die toestand binne afsienbare tyd so te verander dat die P.U. vir C.H.O. ook 'n positiewe bydrae kan mak tot die werk van ander instansies wat op hierdie terrein arbei.

Die middel, personeel en tyd tot ons beskikking dwing ons tot ' $n$ enigsins beskeie begin - heeltemal in ' $n$ lyn met die tradisie van die P.U. vir C.H.O. Daarom stel ek my voor dat ons in hierdie en die volgende akademiese jaar hoofsaaklik besig sal wees om 'n Afrikaorientering te vind en op te bou. Dit sal dus begin met ' $n$ algemene benadering van Afrika om daaraan ' $n$ plek te gee in ons wetenskaplike visie - geografies, histories, demografies, etnologies, ekonomies, e.d.m. maar geleidelik moet dan ook volg 'n diepergaande en meer gespesialiseerde benadering, studie en voordrag. Ons instrument van waarneming sal aanvanklik die teleskoop en later eers die mikroskoop wees. Die heelhartige medewerking van die lede van die seminaar en van ander per- 
soneellede wie se hulp van tyd tot tyd nodig mag word, is noodsaaklik on die gestelde ideale te bereik. Daarop wil ek 'n ernstige beroep doen.

Potchefstroom.

J. H. COETZEE.

8 Augustus 1957. 